\title{
$\left({ }^{3} \mathrm{He}, d\right)$ reaction to bound and quasibound levels in ${ }^{59} \mathrm{Cu}^{\dagger}$
}

\author{
P. K. Bindal, D. H. Youngblood, and R. L. Kozub* \\ Cyclotron Institute and Physics Department, Texas A\& M University, College Station, Texas 77843
}

(Received 12 April 1976)

\begin{abstract}
The ${ }^{58} \mathrm{Ni}\left({ }^{3} \mathrm{He}, d\right){ }^{59} \mathrm{Cu}$ reaction has been studied at bombarding energies of 35 and $39 \mathrm{MeV}$. Excitation energies and angular distributions were measured for levels up to $9.2 \mathrm{MeV}$ in excitation. Distorted-wave-Bornapproximation calculations were performed using resonance form factors for the proton-unstable levels $\left(E_{x} \geq \sim 3.4 \mathrm{MeV}\right)$ in order to make $l$ assignments and to extract the spectroscopic factors. Twelve levels in ${ }^{59} \mathrm{Cu}$ are identified as possible analogs of states in ${ }^{59} \mathrm{Ni}$. A particle-core-coupling model is used to predict the properties of ${ }^{59} \mathrm{Cu}$ and fair agreement with the experiment is obtained.
\end{abstract}

[NUCLEAR REACTIONS, NUCLEAR STRUCTURE $\quad{ }^{58} \mathrm{Ni}\left({ }^{3} \mathrm{He}, d\right) E=35.0,39.1 \mathrm{MeV}$; measured $\sigma(\theta),{ }^{59} \mathrm{Cu}$ levels, deduced $l, S$; identified analog states, calculated $J$, $\pi, S$, particle-core-coupling model.

\section{INTRODUCTION}

The structure of ${ }^{59} \mathrm{Cu}$ has been studied by several groups both experimentally and theoretically. The $\left({ }^{3} \mathrm{He}, d\right),(\alpha, t)$, and $(d, n)$ reactions have been used extensively ${ }^{1-6}$ to obtain spectroscopic information on ${ }^{59} \mathrm{Cu}$. Analyses of these results were generally limited to levels of excitation $54 \mathrm{MeV}$, because the states above $3.4 \mathrm{MeV}$ are proton unstable, and therefore distorted-wave-Bornapproximation (DWBA) calculations could not be performed in the usual manner. However, these studies yielded important spectroscopic information on the low-lying states and the excitation energies of many higher-lying states. In addition, Nelson et al. ${ }^{7}$ have used the ${ }^{58} \mathrm{Ni}\left({ }^{3} \mathrm{He}, d \gamma\right){ }^{59} \mathrm{Cu}$ reaction to determine $J^{\pi}$ and obtain mean lifetimes of levels in ${ }^{59} \mathrm{Cu}$ below $3.6 \mathrm{MeV}$. Considerable information on unbound levels in ${ }^{59} \mathrm{Cu}$ has been obtained ${ }^{8-10}$ by proton elastic scattering on ${ }^{58} \mathrm{Ni}$. Several levels have been identified as possible analogs of levels in ${ }^{59} \mathrm{Ni}$ and their properties measured. Investigation $s^{11-13}$ of the $\gamma$ decay of the levels at $6.842,6.889$, and $6.903 \mathrm{MeV}$ in ${ }^{59} \mathrm{Cu}$ populated with the ${ }^{58} \mathrm{Ni}(p, \gamma){ }^{59} \mathrm{Cu}$ reaction have led to the determination of spin assignments for a few levels above $3.4 \mathrm{MeV}$ in excitation.

There has been considerable speculation ${ }^{1-3}$ about the isospin character of many of the unbound levels observed in proton stripping reactions. The positions and relative strengths were used as criteria for identifying ${ }^{59} \mathrm{Cu}$ states as analogs of states in ${ }^{59} \mathrm{Ni}$; however, spectroscopic factors and $l$ assignments were not available. The most reliable identification of isobaric analog states (IAS) has been done utilizing the elastic scattering ${ }^{9,10}$ and radiative capture data ${ }^{11-13}$ where four states have been identified as analogs on the basis of energy, $J^{\pi}$, and spectroscopic factors.

Unfortunately the study of levels just above threshold is not practical with elastic proton scattering due to the large Coulomb barrier, while even at higher energies states with high $l$ values will be suppressed. The existing elastic scattering data provide no information on unbound states below $E_{x}=5.2 \mathrm{MeV}$ and could easily miss states having higher penetrability above this energy. Stripping reactions however are not very sensitive to the penetrability, as the yield (for a given $l$ ) is essentially proportional to the singleparticle strength of the state with only a slight excitation energy dependence. Techniques have now been developed ${ }^{14,15}$ to analyze stripping reactions populating unbound levels; however most of the published data were taken at relatively low energies where DWBA analysis, particularly of higher excited states, is at best suspect due to the low energy of the outgoing particle. Thus the ${ }^{58} \mathrm{Ni}\left({ }^{3} \mathrm{He}, d\right){ }^{59} \mathrm{Cu}$ reaction was studied at 35 and 39 $\mathrm{MeV}$ incident energies to obtain additional nuclear structure information about the higher excited states in ${ }^{59} \mathrm{Cu}$. Additionally, utilizing the above mentioned DWBA techniques, the existing data for population of unbound levels in ${ }^{59} \mathrm{Cu}$ have been analyzed where practical.

\section{EXPERIMENTAL PROCEDURE}

The experimental details are similar to those described previously. ${ }^{16}$ A $305 \mu \mathrm{g} / \mathrm{cm}^{2}$ self-supporting $\mathrm{Ni}$ foil, enriched to $\sim 99 \%$ in ${ }^{58} \mathrm{Ni}$, was bombarded with 35.0 and $39.1 \mathrm{MeV}{ }^{3} \mathrm{He}$ ions accelerated by the Texas A \& M University cyclotron. Two silicon detector telescopes spaced $5^{\circ}$ apart were used to reduce data acquisition time and 


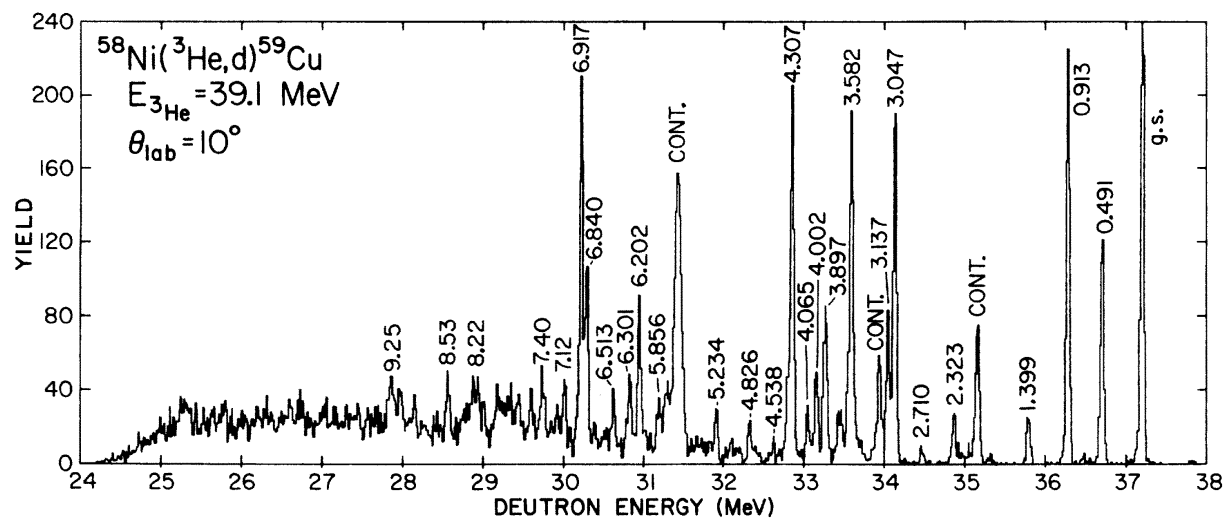

FIG. 1. A spectrum of the ${ }^{58} \mathrm{Ni}\left({ }^{3} \mathrm{He}, d\right){ }^{59} \mathrm{Cu}$ reaction. The excitation energies of the observed states are indicated in $\mathrm{MeV}$.

selected data points were checked by measurements with both systems. The detector telescopes consisted of $2 \mathrm{~mm}(\Delta E)$ and $3 \mathrm{~mm}(E)$ detectors for both stacks. A typical ${ }^{3} \mathrm{He}$ spectrum is shown in Fig. 1. The overall resolution was about 50 $\mathrm{keV}$ full width at half maximum. Due to the high density of levels in the high excitation region, a multipeak fitting program, described previously, ${ }^{17}$ was used in analyzing the data.

\section{DISTORTED-WAVE-BORN-APPROXIMATION CALCULATIONS}

\section{A. Bound states}

DWBA calculations were performed using the computer code DWUCK. ${ }^{18}$ Single-particle wave functions, used as form factors for stripping to bound states in ${ }^{59} \mathrm{Cu}$, were generated in the usual manner by varying the depth of the Woods-Saxon well. The calculations were done both using the zero- range approximation (ZR) and utilizing finiterange and nonlocal (FRNL) corrections. The optical model, form factor, and FRNL parameters are listed in Table I. The calculated and experimental cross sections are related by

$$
\left(\frac{d \sigma}{d \Omega}\right)_{\text {exp }}=\frac{N C^{2} S}{2 J+1}\left(\frac{d \sigma}{d \Omega}\right)_{\mathrm{DW}},
$$

where $J$ is the transferred angular momentum, $N$ is the normalization constant determined from the internal structure of the projectile, and $C^{2} S$ is the spectroscopic factor. We have used values of $N$ $=4.42$ and 1.65 for the $\left({ }^{3} \mathrm{He}, d\right)$ and $(d, n)$ reactions, respectively.

\section{B. Quasibound states}

Levels above $3.4 \mathrm{MeV}$ excitation energy are proton unstable and therefore the usual DWBA computer codes cannot be used to analyze the data. The DWBA form factors needed for these levels were generated by varying the depth of the WoodsSaxon well to produce a resonance at the proper energy having the correct $(l, J) .{ }^{14}$ Zero-range DWBA calculations were performed in the same manner as for the bound states; however, a large cutoff radius $(200 \mathrm{fm})$ is required for convergence of the radial integrals if the exterior amplitude of the form factor is large ( $\geqslant 0.01$ times the interior amplitude). This method is essentially equivalent to that of Vincent and Fortun $\mathrm{e}^{15}$ and has been

TABLE I. Optical model and finite-range nonlocal (FRNL) parameters used in DWBA calculations (in MeV fm).

\begin{tabular}{|c|c|c|c|c|c|c|c|c|c|c|c|}
\hline Particle & $E_{3 \mathrm{He}}$ & $V$ & $r_{0}$ & $a$ & $W$ & $4 W_{D}$ & $r_{I}$ & $a_{I}$ & $r_{c}$ & $\beta^{\mathrm{a}}$ & $R^{\mathbf{b}}$ \\
\hline${ }^{3} \mathrm{He}^{\mathrm{c}}$ & 39 & 169.5 & 1.15 & 0.752 & 22.09 & & 1.57 & 0.787 & 1.40 & 0.20 & \\
\hline$d^{\mathrm{d}}$ & 39 & 103.6 & 1.048 & 0.825 & & 47.52 & 1.252 & 0.888 & 1.30 & 0.54 & 0.695 \\
\hline${ }^{3} \mathrm{He}^{\mathrm{e}}$ & 35 & 162.0 & 1.193 & 0.686 & 20.3 & & 1.536 & 0.901 & 1.40 & 0.20 & \\
\hline$d^{\mathrm{f}}$ & 35 & 96.83 & 1.081 & 0.814 & & 51.6 & 1.295 & 0.784 & 1.30 & 0.54 & 0.695 \\
\hline$p$ & & & 1.20 & 0.65 & & $\lambda_{\text {so }}=25$ & & & & 0.85 & \\
\hline
\end{tabular}

a Nonlocal parameters used in DwUCK.

${ }^{b}$ Finite-range parameters.

${ }^{c}$ Reference 19.

d Reference 20 .

e Reference 21.

f Reference 22 . 
TABLE II. Summary of spectroscopic factors for bound states of ${ }^{59} \mathrm{Cu}$.

\begin{tabular}{|c|c|c|c|c|c|c|c|c|}
\hline \multirow{2}{*}{$\begin{array}{c}{ }^{59} \mathrm{Cu}^{* \mathrm{a}} \\
E_{x} \\
(\mathrm{MeV} \pm \mathrm{keV})\end{array}$} & \multirow[b]{2}{*}{$l_{p}$} & \multirow[b]{2}{*}{$J^{\pi \mathrm{b}}$} & \multicolumn{3}{|c|}{$\left({ }^{3} \mathrm{He}, d\right)$} & \multicolumn{2}{|c|}{$(d, n)$} & \multirow{2}{*}{$\begin{array}{c}\quad\left({ }^{3} \mathrm{He}, d\right) \\
\text { Avg. (FRNL) a, }\end{array}$} \\
\hline & & & $39 \mathrm{MeV}^{\mathrm{a}, \mathrm{c}}$ & $35 \mathrm{MeV}^{\mathrm{a}, \mathrm{c}}$ & $16.4 \mathrm{MeV}^{\mathrm{c}, \mathrm{d}}$ & $7 \mathrm{MeV}^{\mathrm{c}, \mathrm{e}}$ & $10 \mathrm{MeV}^{\mathrm{c}, \mathrm{f}}$ & \\
\hline 0.0 & 1 & $\frac{3}{2}^{-}$ & 1.89 & 1.81 & 2.1 & 1.85 & 1.47 & 1.28 \\
\hline $0.491 \pm 5$ & 1 & $\frac{1}{2}^{-}$ & 0.59 & 1.0 & 1.1 & 0.84 & 0.64 & 0.72 \\
\hline $0.913 \pm 7$ & 3 & $\frac{5}{2}^{-}$ & 2.85 & 3.33 & 4.0 & 2.5 & 2.27 & 2.62 \\
\hline $1.399 \pm 7$ & 3 & $\frac{7}{2}^{-}$ & 0.31 & 0.31 & 0.53 & $0.4 \pm 0.1$ & 0.59 & 0.24 \\
\hline $2.323 \pm 7$ & 1 & $\frac{3}{2}^{-}$ & 0.29 & 0.25 & 0.26 & 0.20 & 0.18 & 0.17 \\
\hline $2.710 \pm 7$ & 3 & $\frac{7}{2}^{-}$ & 0.15 & 0.11 & 0.12 & $\leq 0.3$ & 0.14 & 0.08 \\
\hline $3.047 \pm 7$ & 4 & $\frac{9}{2}^{+}$ & 3.96 & 2.94 & 3.1 & 2.4 & 1.78 & 2.27 \\
\hline $3.137 \pm 7$ & 1 & $\frac{1}{2}^{-}$ & 0.32 & & 0.40 & 0.22 & 0.16 & 0.29 \\
\hline
\end{tabular}

${ }^{a}$ Present work.

${ }^{\mathrm{b}} J^{\pi}$ assignments taken from Ref. 7 .

${ }^{c}$ DWBA analysis using the zero-range approximation.

${ }^{\mathrm{d}}$ Reference 3 .

e Reference 5 .

${ }^{f}$ Reference 4.

g Average of the $(2 J+1) C^{2} S_{p}$ obtained from the 35 and $39 \mathrm{MeV}$ data using FRNL.

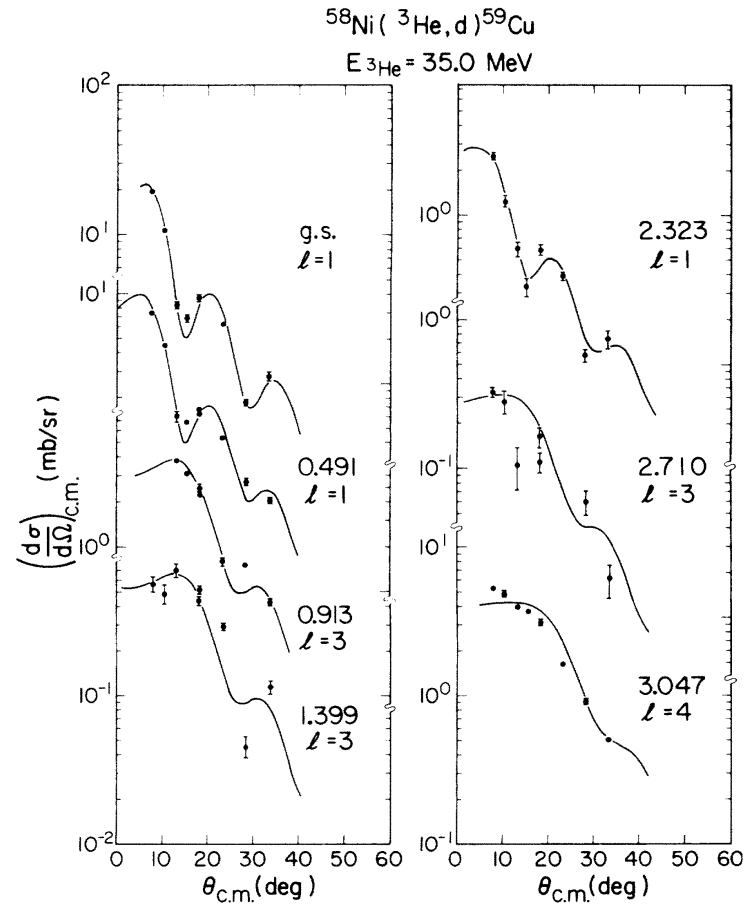

FIG. 2. Angular distributions for the ${ }^{58} \mathrm{Ni}\left({ }^{3} \mathrm{He}, d\right){ }^{59} \mathrm{Cu}$ reaction leading to bound states. The excitation energies are indicated in $\mathrm{MeV}$. The errors shown are statistical only. The curves are FRNL DWBA predictions for the $l$ transfer indicated.

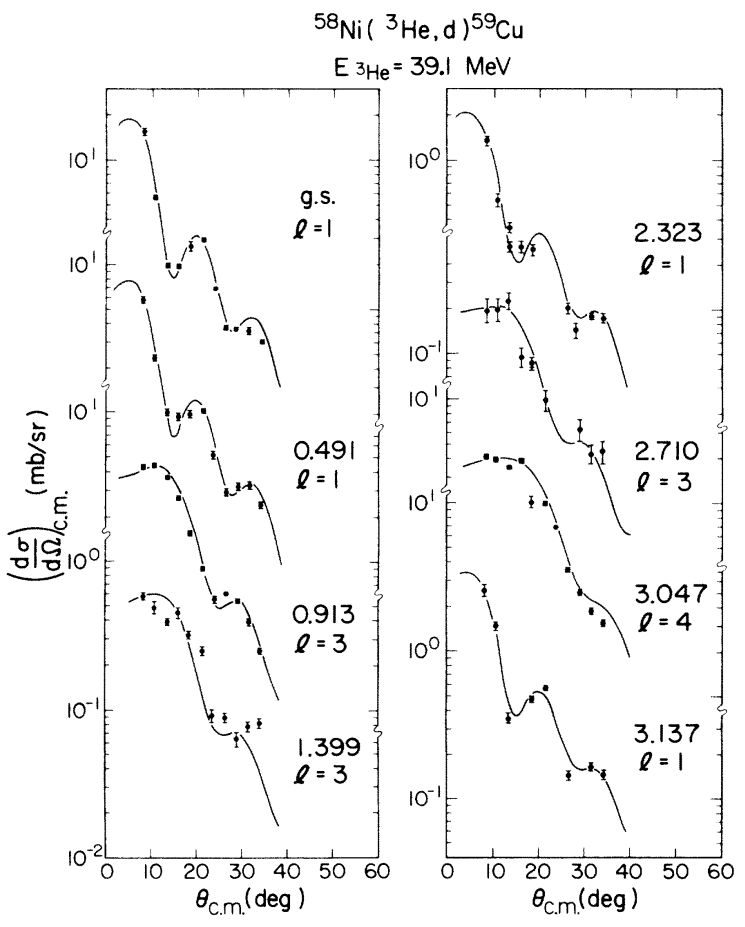

FIG. 3. Angular distributions for the ${ }^{58} \mathrm{Ni}\left({ }^{3} \mathrm{He}, d\right){ }^{59} \mathrm{Cu}$ reaction leading to bound states. See Fig. 2 caption. 
TABLE III. Summary of experimental results for states of ${ }^{59} \mathrm{Cu}$ with $E_{x} \geq 3.4 \mathrm{MeV}$.

\begin{tabular}{|c|c|c|c|c|c|c|c|c|c|c|}
\hline \multirow{3}{*}{$\begin{array}{c}{ }^{59} \mathrm{Cu}^{*} \\
(\mathrm{MeV} \pm \mathrm{keV})\end{array}$} & \multirow[b]{3}{*}{$l_{p}$} & \multirow[b]{3}{*}{$J^{\pi \mathrm{e}}$} & \multicolumn{3}{|c|}{$G_{l j}^{\mathrm{a}}$} & \multicolumn{2}{|c|}{$(p, \gamma)$} & \multicolumn{3}{|c|}{ Nuclear Data ${ }^{b}$} \\
\hline & & & \multicolumn{2}{|c|}{$\left({ }^{3} \mathrm{He}, d\right){ }^{\mathrm{c}}$} & \multirow{2}{*}{$\begin{array}{r}(d, n)^{\mathrm{d}} \\
10 \mathrm{MeV}\end{array}$} & \multirow{2}{*}{$\begin{array}{c}E_{x} \\
(\mathrm{MeV})\end{array}$} & \multirow[b]{2}{*}{$J^{\pi}$} & \multirow{2}{*}{$\begin{array}{c}E_{x} \\
(\mathrm{MeV} \pm \mathrm{keV})\end{array}$} & \multirow[b]{2}{*}{$l_{p}$} & \multirow[b]{2}{*}{$G_{l j}^{\mathrm{a}}$} \\
\hline & & & $39 \mathrm{MeV}$ & $35 \mathrm{MeV}$ & & & & & & \\
\hline (3.44) & & & & & & & & $3.435 \pm 12$ & & \\
\hline (3.52) & & & & & & & & $3.558 \pm 8$ & & \\
\hline $3.582 \pm 8$ & 2 & $\frac{5}{2}^{+}$ & 1.05 & 1.22 & 1.34 & & & $3.586 \pm 6$ & 2 & 0.76 \\
\hline$(3.62)$ & & & & & & & & $3.629 \pm 8$ & & \\
\hline $3.707 \pm 12$ & 2 & $\frac{5}{2}^{+}$ & $(0.12)$ & 0.17 & & 3.663 & $\frac{1}{2}, \frac{3}{2}^{\mathrm{f}}$ & $3.671 \pm 25$ & & \\
\hline $3.737 \pm 8$ & 1 & $\frac{3}{2}^{-}$ & $(0.12)$ & & & 3.742 & $\leq \frac{5}{2} \mathrm{f}$ & $3.749 \pm 8$ & 1 & 0.14 \\
\hline $3.897 \pm 7$ & 1 & $\frac{3}{2}^{-}$ & $0.45^{\mathrm{g}}$ & 0.54 & & 3.905 & $\frac{3}{2} \mathrm{f}$ & $3.901 \pm 8$ & 1 & 0.52 \\
\hline & & & & & & & & $3.916 \pm 10$ & 2 & 0.40 \\
\hline $4.002 \pm 7$ & 1 & $\frac{3}{2}^{-}$ & 0.25 & 0.27 & 0.31 & & & $4.007 \pm 6$ & 1 & 0.36 \\
\hline$(4.06)$ & 3 & $\frac{5}{2}^{-}$ & & & 0.69 & & & $4.058 \pm 6$ & (3) & 0.3 \\
\hline \multirow[t]{2}{*}{$4.116 \pm 7$} & 3 & $\frac{5}{2}^{-}$ & 0.14 & & & $4.131^{\mathrm{h}}$ & & $4.116 \pm 6$ & $(2,3)$ & \\
\hline & 1 & $\frac{3}{2}^{-}$ & & & 0.1 & & & & & \\
\hline $4.261^{\mathrm{d}}$ & 1 & $\frac{3}{2}^{-}$ & & & 0.05 & & & $4.267 \pm 8$ & & \\
\hline $4.307 \pm 7$ & 3 & $\frac{5}{2}^{-}$ & $1.05^{\mathrm{g}}$ & 1.36 & 1.04 & 4.302 & $\frac{5}{2}, \frac{7}{2}^{h}$ & $4.313 \pm 6$ & 3 & 1.67 \\
\hline $4.358 \pm 10$ & 1 & $\frac{1}{2}^{-}$ & $0.30 \mathrm{~g}$ & & 0.29 & & & $4.362 \pm 6$ & 1 & 0.36 \\
\hline $4.538 \pm 10$ & 3 & $\frac{5}{2}^{-}$ & 0.09 & 0.14 & $(0.20)$ & $4.530^{\mathrm{h}}$ & & $4.550 \pm 15$ & & \\
\hline$(4.70)$ & 3 & $\frac{5}{2}^{-}$ & & & 0.15 & $(4.689)^{b}$ & & $4.720 \pm 15$ & & \\
\hline$(4.77)$ & & & & & & & & $4.777 \pm 15$ & & \\
\hline $4.828 \pm 10$ & 1 & $\frac{3}{2}^{-}$ & 0.12 & 0.12 & 0.15 & & & $4.846 \pm 15$ & (1) & \\
\hline $5.058 \pm 10$ & 1 & $\frac{1}{2}^{-}$ & 0.08 & 0.08 & & & & $5.063 \pm 15$ & & \\
\hline $5.234 \pm 10$ & 1 & $\frac{1}{2}^{-}$ & 0.18 & 0.20 & 0.18 & & & $5.248 \pm 15$ & & \\
\hline \multirow[t]{2}{*}{$(5.30)$} & & & & & & & & $5.321 \pm 15$ & & \\
\hline & & & & & & & & $5.502 \pm 15$ & & \\
\hline$(5.61)$ & & & & & & & & $5.625 \pm 15$ & & \\
\hline $5.681 \pm 10$ & 3 & $\frac{5}{2}^{-}$ & 0.14 & 0.20 & & & & $5.680 \pm 15$ & & \\
\hline $5.856 \pm 10$ & 3 & $\frac{5}{2}^{-}$ & 0.15 & & 0.84 & & & $5.868 \pm 15$ & & \\
\hline $5.953 \pm 10$ & 1 & $\frac{1}{2}^{-}$ & 0.12 & & & & & & & \\
\hline$(6.11)$ & (4) & $\frac{9}{2}^{+}$ & & & $(0.50)$ & & & $6.124 \pm 20$ & & \\
\hline \multirow[t]{2}{*}{$6.202 \pm 10$} & (3) & $\frac{5}{2}^{-}$ & 0.41 & 0.57 & & & & $6.204 \pm 20$ & & \\
\hline & $(4)$ & $\frac{9}{2}^{+}$ & & 0.48 & 1.05 & & & & & \\
\hline $6.301 \pm 12$ & 4 & $\frac{9}{2}^{+}$ & 0.20 & & & & & $6.314 \pm 20$ & & \\
\hline \multirow[t]{2}{*}{$(6.35)$} & (4) & $\frac{9}{2}^{+}$ & $(0.07)$ & & & & & & & \\
\hline & (1) & $\frac{1}{2}^{+}$ & $(0.13)$ & & & & & & & \\
\hline $6.513 \pm 12$ & 3 & $\frac{5}{2}^{-}$ & $(0.21)$ & 0.28 & & & & $6.525 \pm 20$ & & \\
\hline$(6.73)$ & & & & & & & & $6.740 \pm 20$ & & \\
\hline $6.840 \pm 12$ & 4 & $\frac{9}{2}^{+}$ & 0.39 ) & & & & & $6.845 \pm 20$ & & \\
\hline $6.917 \pm 12$ & 4 & $\frac{9}{2}^{+}$ & $0.70\}$ & $0.95^{\mathrm{g}}$ & & 6.902 & $\frac{9}{2}^{+} f, g, i$ & $6.910 \pm 20$ & & \\
\hline $7.116 \pm 12$ & 2 & $\frac{5}{2}^{+}$ & 0.13 & 0.16 & & & & $7.128 \pm 20$ & & \\
\hline $\begin{array}{l}7.155 \pm 15 \\
(7.20)\end{array}$ & $(2)$ & $\frac{5}{2}^{+}$ & $(0.12)$ & & & & & & & \\
\hline$(7.26)$ & & & & & & & & & & \\
\hline $7.397 \pm 15$ & $(2)$ & $\frac{5}{2}^{+}$ & $(0.13)$ & & & & & & & \\
\hline & (4) & $\frac{9}{2}^{+}$ & $(0.14)$ & & & & & & & \\
\hline $\begin{array}{l}(7.68) \\
8.103 \pm 20\end{array}$ & $(2)$ & $\frac{5}{2}^{+}$ & 0.09 & & & & & & & \\
\hline
\end{tabular}


TABLE III (Continued)

\begin{tabular}{|c|c|c|c|c|c|c|c|c|c|c|}
\hline \multirow{3}{*}{$\begin{array}{c}{ }^{59} \mathrm{Cu}^{*} \\
(\mathrm{MeV} \pm \mathrm{keV})\end{array}$} & \multirow[b]{3}{*}{$l_{p}$} & \multirow[b]{3}{*}{$J^{\pi \mathrm{e}}$} & \multicolumn{3}{|c|}{$G_{l j}^{\mathrm{a}}$} & \multicolumn{2}{|c|}{$(p, \gamma)$} & \multicolumn{3}{|c|}{ Nuclear Data ${ }^{b}$} \\
\hline & & & & & $(d, n)^{\mathrm{d}}$ & $E_{x}$ & & & & \\
\hline & & & $39 \mathrm{MeV}$ & $35 \mathrm{MeV}$ & $10 \mathrm{MeV}$ & $(\mathrm{MeV})$ & $J^{\pi}$ & $(\mathrm{MeV} \pm \mathrm{keV})$ & $l_{p}$ & $G_{l j}{ }^{\mathrm{a}}$ \\
\hline $8.169 \pm 20$ & 2 & $\frac{5}{2}^{+}$ & 0.12 & & & & & & & \\
\hline $\begin{array}{l}8.223 \pm 20 \\
(8.26)\end{array}$ & 2 & $\frac{5}{2}^{+}$ & 0.11 & & & & & & & \\
\hline $\begin{array}{l}8.532 \pm 20 \\
(9.18)\end{array}$ & 4 & $\frac{9}{2}^{+}$ & 0.13 & & & & & & & \\
\hline $9.252 \pm 20$ & 4 & $\frac{9}{2}^{+}$ & 0.12 & & & & & & & \\
\hline
\end{tabular}

${ }^{\mathrm{a}} G_{l j}=(2 J+1) C^{2} S_{p}$.

${ }^{\mathrm{b}}$ Reference 23 .

c Present work.

${ }^{d}$ Present analysis of the data in Ref. 4.

e $J^{\pi}$ values are those which seem most plausible on a shell-model basis; no assignments have been made.

${ }^{\mathrm{f}}$ Reference 13 .

$\mathrm{g}$ Analysis of the experimental data of Blair and Armstrong (Ref. 1) gave $(2 J+1) C^{2} S_{p}=0.62,1.4,0.31$, and 0.85 for the $3.88,4.30,4.36$, and $6.86 \mathrm{MeV}$ states, respectively. They did not resolve the two levels at $\sim 6.9 \mathrm{MeV}$.

${ }^{\mathrm{h}}$ Reference 11 .

${ }^{\mathrm{i}}$ Reference 12 .

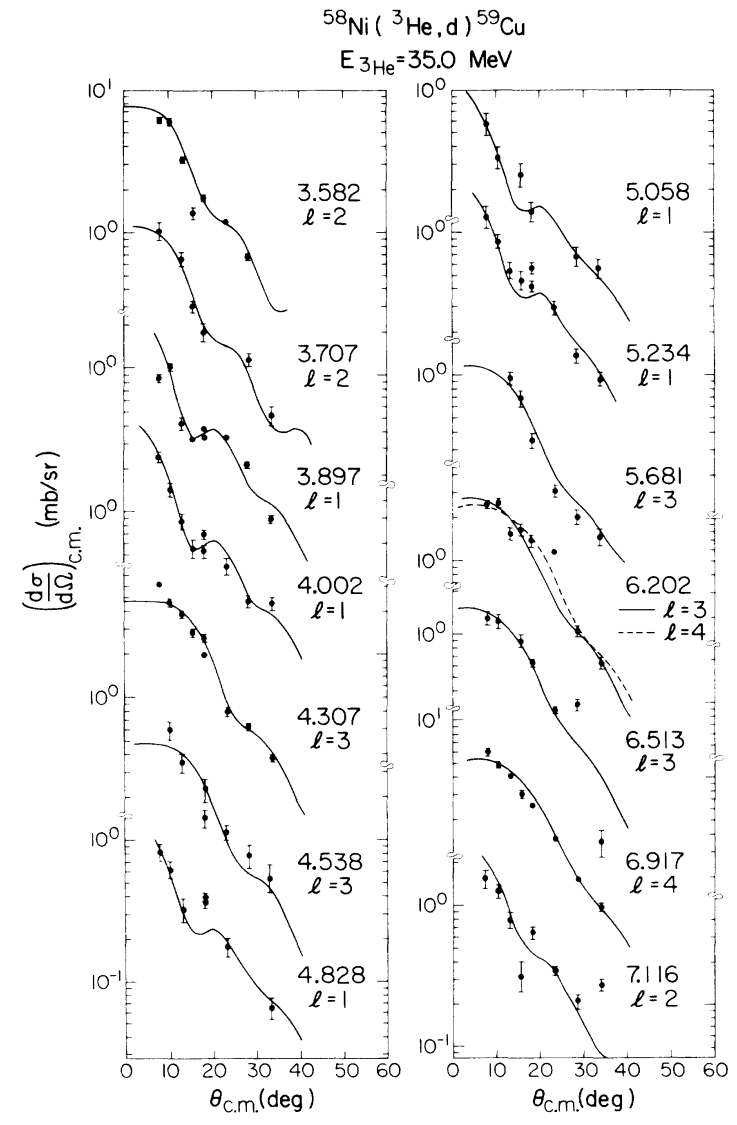

FIG. 4. Angular distributions for the ${ }^{58} \mathrm{Ni}\left({ }^{3} \mathrm{He}, d\right){ }^{59} \mathrm{Cu}$ reaction leading to quasibound states. The excitation energies are indicated in MeV. The curves are DWBA predictions for the $l$ transfer indicated obtained as described in the text.

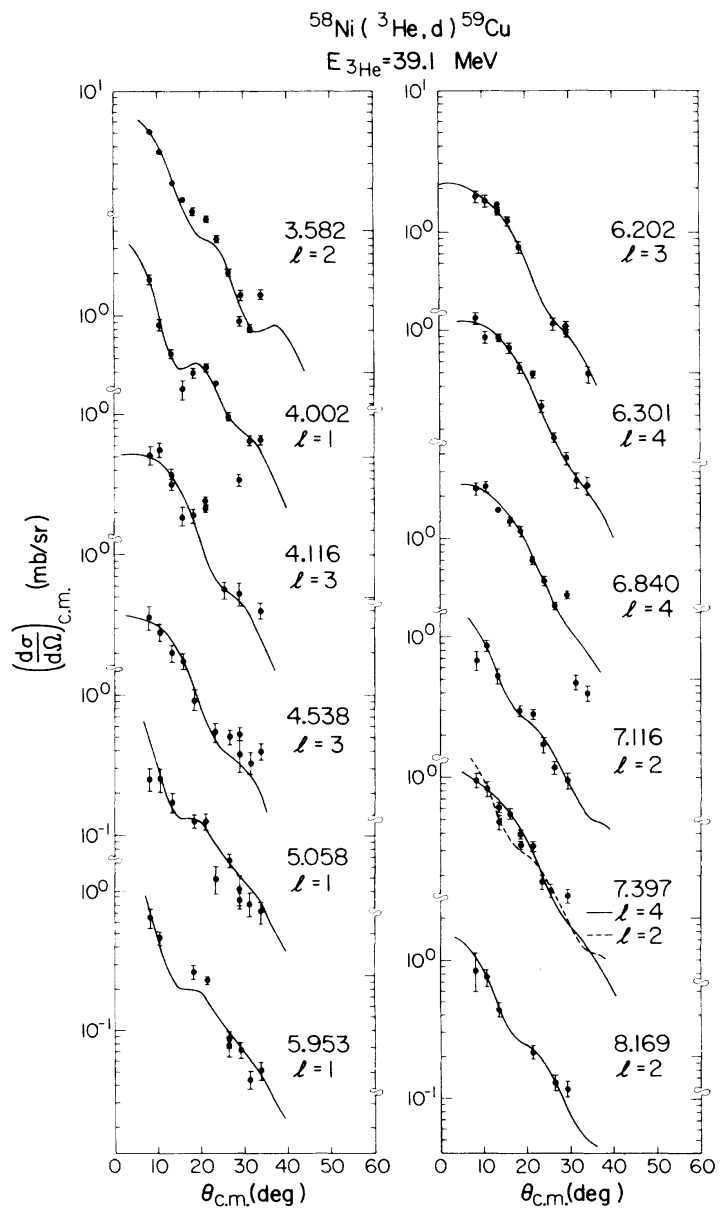

FIG. 5. Angular distributions for the ${ }^{58} \mathrm{Ni}\left({ }^{3} \mathrm{He}, d\right){ }^{59} \mathrm{Cu}$ reaction leading to quasibound states. See Fig. 4 caption. 


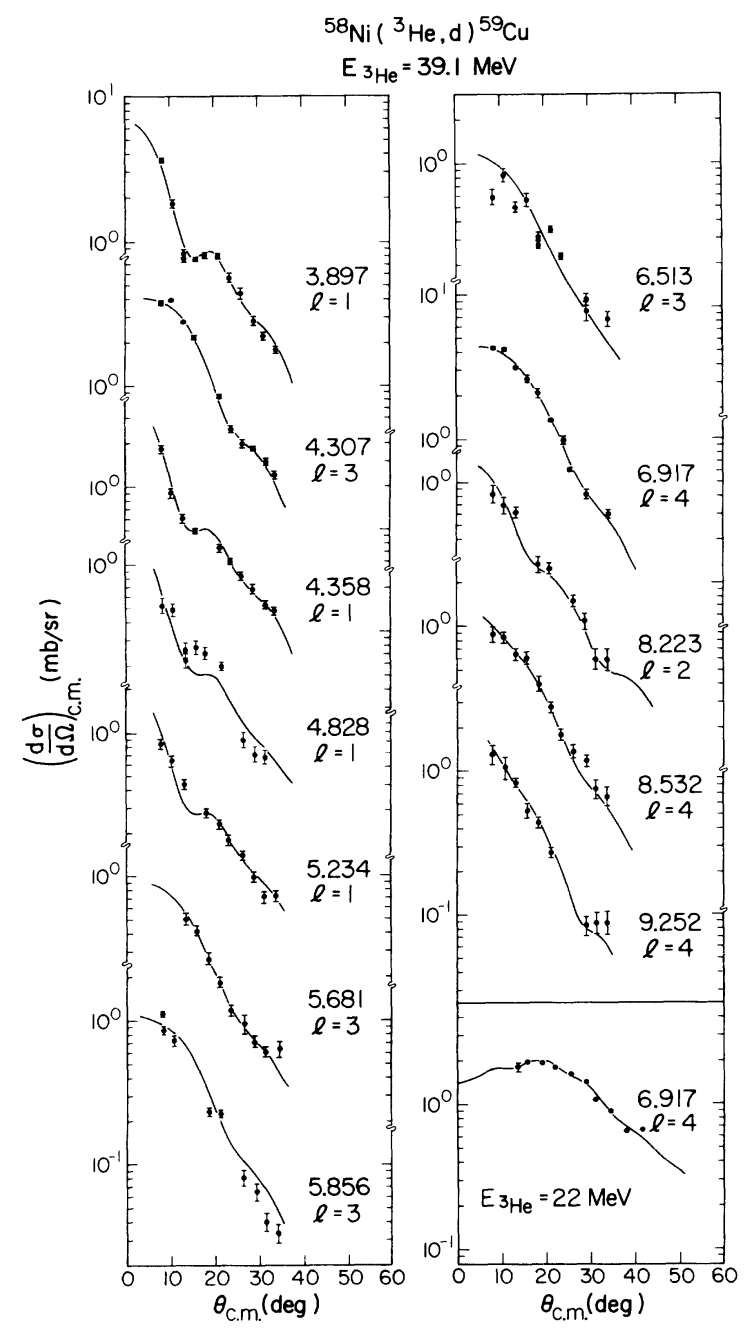

FIG. 6. Angular distributions for the ${ }^{58} \mathrm{Ni}\left({ }^{3} \mathrm{He}, d\right){ }^{59} \mathrm{Cu}$ reaction leading to the possible analogs of ${ }^{59} \mathrm{Ni}$. See Fig. 4 caption.

quite successful for the $\left({ }^{3} \mathrm{He}, d\right)$ reaction to unbound states in several nuclei. ${ }^{14,16}$ It has also been demonstrated ${ }^{16}$ that the same technique is adequate for analog states; that is, no special treatment of the form factor for the analog state is necessary to obtain reliable spectroscopic information.

\section{DISCUSSION OF RESULTS}

\section{A. Bound states}

A summary of the experimental results for levels below $3.4 \mathrm{MeV}$ in excitation is given in Table II. Angular distributions and DWBA predictions are shown in Figs. 2 and 3 for the 35 and $39 \mathrm{MeV}$ data, respectively. The data are fitted reasonably well. The spectroscopic factors obtained in the present study are compared with previous work ${ }^{3-5}$ in Table II. The $J^{x}$ assignments are taken from the $\left({ }^{3} \mathrm{He}, d \gamma\right)$ work of Nelson et al. ${ }^{7}$ Our energy locations, $l$ values, and spectroscopic factors obtained using ZR DWBA agree reasonably well with the previous work (which also used ZR DWBA) for all the states. The fits obtained with FRNL calculations were slightly better and the spectroscopic factors decreased somewhat.

\section{B. Quasibound states}

A summary of the results obtained in the present study for levels above $3.4 \mathrm{MeV}$ in ${ }^{59} \mathrm{Cu}$ is given in Table III and compared with existing information from the literature. Weak levels observed only at a few angles are shown in parentheses. For $E_{x} \geqslant 7.12 \mathrm{MeV}$ only the stronger states were analyzed. Many weaker states obviously present could not be resolved and are not included in the table. Angular distributions and DWBA predictions for the $35 \mathrm{MeV}$ data are shown in Fig. 4 . The DWBA fits to the $39 \mathrm{MeV}$ data are shown in Figs. 5 and 6 . In addition to analyzing the present $\left({ }^{3} \mathrm{He}, d\right)$ data, we also analyzed states above 3.4 $\mathrm{MeV}$ in excitation populated in the $(d, n)$ reaction of Marusak ${ }^{4}$ with $E_{d}=10 \mathrm{MeV}$ and the $\left({ }^{3} \mathrm{He}, d\right)$ reaction of Blair and Armstrong ${ }^{1}$ with $E_{3_{\mathrm{He}}}=22 \mathrm{MeV}$. A fit to the $6.917 \mathrm{MeV}$ state excited in the Blair and Armstrong work is also shown in Fig. 6. Representative fits to the Marusak data for the $(d, n)$ reaction for four different $l$ transfers are shown in Fig. 7.

In previous work, spectroscopic factors and $l$ value assignments for some of the levels between 3.4 and $4.4 \mathrm{MeV}$ excitation were obtained from proton transfer reaction studies by comparing with DWBA calculations performed assuming the states

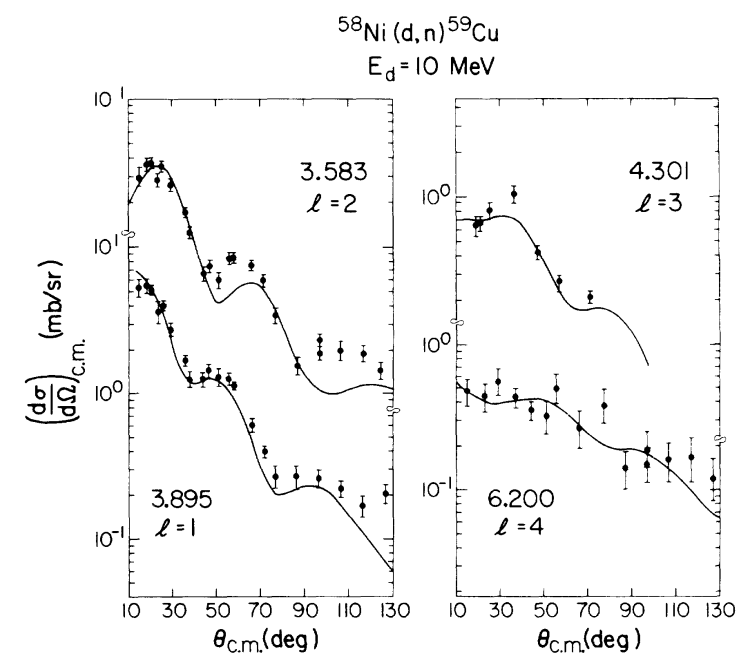

FIG. 7. Angular distributions for the ${ }^{58} \mathrm{Ni}(d, n){ }^{59} \mathrm{Cu}$ reaction leading to quasibound states. The experimental data are from Ref. 4. See Fig. 4 caption. 
were bound by a small amount. These results are generally in good agreement with the values we obtain as can be seen in Table III.

There is excellent agreement on $l$ assignments for all the levels from the analysis of the four different sets of data except for the 4.116 and 6.202 $\mathrm{MeV}$ levels. An $l=3$ assignment is favored for the 4.116 $\mathrm{MeV}$ level from the $\left({ }^{3} \mathrm{He}, d\right)$ reaction data whereas an $l=1$ assignment is favored from the $(d, n)$ data. Some $l=1$ contribution cannot be ruled out in our data. In the case of the $6.202 \mathrm{MeV}$ level, the $35 \mathrm{MeV}$ data are fitted equally well by $l=3$ and $l=4$ transfers, whereas the $39 \mathrm{MeV}$ data are fitted better by an $l=3$ transfer and the $(d, n)$ reaction data are fitted better by an $l=4$ transfer. However, the analysis of the $(d, n)$ reaction leading to such highly excited levels is not very trustworthy as the outgoing neutron is left with so little energy that the usual DWBA is probably not applicable here. This may be the reason that the spectroscopic factors extracted from the $(d, n)$ reaction for levels above $5.3 \mathrm{MeV}$ are very high as compared to those obtained from the analyses of the 35 and $39 \mathrm{MeV}\left({ }^{3} \mathrm{He}, d\right)$ reaction data. The present analysis shows that except for the two levels at 3.58 and $3.71 \mathrm{MeV}$, which are $l=2$, all the levels up to $6 \mathrm{MeV}$ in excitation correspond to $l=1$ transfer (possible $2 p_{1 / 2}$ and $2 p_{3 / 2}$ ) or $l=3$ transfer $\left(1 f_{5 / 2}\right)$. Most of the levels between 6.0 and 7.2 $\mathrm{MeV}$ are $l=4$ (probably $1 g_{9 / 2}$ ), and at higher excitation both $l=2$ and $l=4$ states are excited.

Levels observed with the $(p, \gamma)$ reaction ${ }^{11-13}$ relevant to this work are also included in Table III. Unfortunately, many of the levels reported in these investigations are weakly excited in the present work and for these no meaningful com-

TABLE IV. Spectroscopic factors from ${ }^{58} \mathrm{Ni}(p, p)$ (Ref. 10) obtained using single-particle widths from the optical model.

\begin{tabular}{ccccc}
\hline \hline $\begin{array}{c}E_{p} \\
(\mathrm{MeV})\end{array}$ & $\begin{array}{c}{ }^{59} \mathrm{Cu}^{*} \\
(\mathrm{MeV})\end{array}$ & $J^{\pi}$ & \multicolumn{1}{c}{$\begin{array}{c}\Gamma_{\text {s.p. }} \\
(\mathrm{keV})\end{array}$} & $(2 J+1) C^{2} S$ \\
\hline 3.353 & 6.714 & $\frac{1}{2}^{-}$ & 82.8 & 0.0039 \\
3.878 & 7.228 & $\frac{1}{2}^{-}$ & 206.0 & 0.0061 \\
3.742 & 7.094 & $\frac{3}{2}^{-}$ & 177.2 & 0.0071 \\
3.934 & 7.283 & $\frac{3}{2}^{-}$ & 241.3 & 0.0025 \\
3.835 & 7.186 & $\frac{3}{2}^{+}$ & 59.7 & 0.13 \\
3.911 & 7.261 & $\frac{3}{2}^{+}$ & 67.9 & 0.075 \\
3.369 & 6.728 & $\frac{5}{2}^{+}$ & 28.4 & 0.032 \\
3.752 & 7.100 & $\frac{5}{2}^{+}$ & 59.4 & 0.18 \\
3.473 & 6.830 & $\frac{9}{2}^{+}$ & 0.251 & 0.34 \\
3.545 & 6.900 & $\frac{9}{2}^{+}$ & 0.302 & 0.57 \\
\hline \hline
\end{tabular}

parison is possible. Arai, Ogawa, and Sato ${ }^{10}$ have reported many resonances in ${ }^{59} \mathrm{Cu}$ using ${ }^{58} \mathrm{Ni}(p, p)$ in the excitation region of 6.5 to $7.4 \mathrm{MeV}$. We have calculated the single-particle laboratory widths for the strong resonances using an optical model $^{16}$ with the same potentials as those used for the corresponding DWBA form factor. Using the experimental widths, we have extracted the values of $(2 J+1) C^{2} S=(2 J+1) \Gamma_{p} / \Gamma_{\text {s. p. }}$ expected for these resonances (Table IV). Our spectroscopic factors and $l$ assignments for the $\frac{9}{2}{ }^{+}$states at 6.84 and $6.92 \mathrm{MeV}$ (well resolved at $39 \mathrm{MeV}$, but not at $35 \mathrm{MeV}$ ) and the $\frac{5}{2}^{+}$state at $7.1 \mathrm{MeV}$ are in agreement with $(p, p)$ results. The $\frac{3}{2}+$ states at 7.19 and $7.26 \mathrm{MeV}$ are observed at a few angles but, as expected from their low $(p, p)$ spectroscopic factors, were too weak to obtain definitive angular distributions. The rest of the states would be too weak to observe in the present study.

\section{Isobaric analog states}

Excitation of both $T=\frac{1}{2}\left(T_{<}\right)$and $T=\frac{3}{2}\left(T_{>}\right)$states in ${ }^{59} \mathrm{Cu}$ is isospin allowed with the ${ }^{58} \mathrm{Ni}\left({ }^{3} \mathrm{He}, d\right)$ reaction. Accounting for the Coulomb displacement energy, the analog of the ground state of ${ }^{59} \mathrm{Ni}$ $\left(J^{\pi}=\frac{3}{2}^{-}\right)$should lie at about $3.91 \mathrm{MeV}$ in ${ }^{59} \mathrm{Cu}$, and there has been considerable speculation regarding the analog correspondence. The states $\left(T_{\iota}\right)$ below

TABLE V. Spectroscopic factors for analog states.

\begin{tabular}{|c|c|c|c|c|c|c|}
\hline $\begin{array}{l}{ }^{59} \mathrm{Cu} * \\
(\mathrm{MeV})\end{array}$ & $l_{p}$ & $J^{\pi}$ & ${\overline{G_{l j}^{P}}}^{a}$ & $\begin{array}{c}{ }^{59} \mathrm{Ni}^{*}+3.910^{\mathrm{b}} \\
(\mathrm{MeV})\end{array}$ & $J^{\pi}$ & $\overline{G_{l j}^{n}} c$ \\
\hline 3.897 & 1 & $\frac{3}{2}^{-}$ & 0.52 & 3.910 & $\frac{3}{2}^{-}$ & 0.97 \\
\hline$(3.7-4.0$ & 1 & $\frac{3}{2}^{-}$ & $0.95)$ & & & \\
\hline 4.307 & 3 & $\frac{5}{2}^{-}$ & 1.20 & 4.250 & $\frac{5}{2}^{-}$ & 1.48 \\
\hline 4.358 & 1 & $\frac{1}{2}^{-}$ & 0.30 & 4.375 & $\frac{1}{2}^{-}$ & 0.42 \\
\hline 4.828 & 1 & $\frac{3}{2}^{-}$ & 0.13 & 4.791 & $\frac{3}{2}^{-}$ & 0.10 \\
\hline 5.234 & 1 & $\frac{1}{2}^{-}$ & 0.19 & 5.308 & $\frac{1}{2}^{-}$ & 0.18 \\
\hline 5.681 & 3 & $\frac{5}{2}^{-}$ & 0.17 & 5.593 & $\frac{5}{2}^{-}$ & 0.21 \\
\hline 5.856 & 3 & $\frac{5}{2}^{-}$ & 0.15 & 5.861 & $\left(\frac{7}{2}^{-}\right)$ & 0.10 \\
\hline 6.513 & 3 & $\frac{5}{2}^{-}$ & 0.24 & 6.544 & $\left(\frac{7}{2}^{-}\right)$ & 0.10 \\
\hline 6.917 & 4 & $\frac{9}{2}^{+}$ & 0.70 & 6.970 & $\frac{9}{2}^{+}$ & 2.94 \\
\hline 8.22 & 2 & $\frac{5}{2}^{+}$ & 0.09 & 8.414 & $\frac{5}{2}^{+}$ & 0.48 \\
\hline 8.53 & 4 & $\frac{9}{2}^{+}$ & 0.13 & 8.605 & $\frac{9}{2}^{+}$ & 0.28 \\
\hline 9.25 & 4 & $\frac{9}{2}^{+}$ & 0.12 & 9.361 & $\frac{9}{2}^{+}$ & 0.30 \\
\hline \multicolumn{7}{|c|}{$\begin{array}{l}\text { a } \overline{G_{l j}^{p}}=(2 J+1) C^{2} S_{p} \text {, averages of the spectroscopic fac- } \\
\text { ors given in Table III. } \\
\text { b } 59 \text { Ni excitation energies from Ref. } 26 \text {. } \\
\left.\text { c } \bar{G}_{l j}^{n}=(2 J+1) / 2 T+1\right) C^{2} S_{n} \text {, averages of the spectroscop- } \\
\text { c factors obtained from Refs. } 24-26 \text {. }\end{array}$} \\
\hline
\end{tabular}


$4 \mathrm{MeV}$ do not nearly exhaust all the strength of the $2 p_{1 / 2}, 2 p_{3 / 2}, 1 f_{5 / 2}$, and $1 g_{9 / 2}$ orbitals however, so considerable $T_{<}$strength is expected to lie in the same excitation energy region as the $T>$ states. This makes it difficult to identify the $T>$ levels in ${ }^{59} \mathrm{Cu}$. We have utilized the information on the energy locations, $J^{\pi}$ assignments, and spectroscopic factors obtained in the present analysis and compared it to the information known in ${ }^{59} \mathrm{Ni}$ to identify some of the analog states in ${ }^{59} \mathrm{Cu}$. This information is summarized in Table $\mathrm{V}$ and relevant angular distributions are shown in Figs. 4 and 6 . The energy and $J^{\pi}$ assignments for all the states listed here agree well with that expected from ${ }^{59} \mathrm{Ni}$. These results generally agree with previous identification of the analogs, although several additional ones are located. The averages of the spectroscopic factors obtained for ${ }^{59} \mathrm{Cu}$ using different reactions (Table III) are compared with the averages of the spectroscopic factors for ${ }^{59} \mathrm{Ni}$ obtained from the studies of Fulmer et al., ${ }^{24}$ Cosman et al. ${ }^{25}$ and Chowdhury and Sen Gupta. ${ }^{26}$ For low-lying analog states, the spectroscopic factors agree well; however, for higher excited states, they are somewhat lower than those predicted using the ${ }^{59} \mathrm{Ni}$ data. The largest discrepancy exists for the $6.917 \mathrm{MeV}$ state in ${ }^{59} \mathrm{Cu}$ which has been identified to be the analog of the $\frac{9}{2}^{+}, 3.06$ $\mathrm{MeV}$ state in ${ }^{59} \mathrm{Ni}$ by $(p, \gamma)$ studies. The observed spectroscopic factors for this state are only about $24 \%$ of the value expected from the ${ }^{59} \mathrm{Ni}$ data. In the recent study of ${ }^{58} \mathrm{Ni}(p, p)$ by Arai et al. ${ }^{10}$ the $g_{9 / 2}$ resonance at $E_{p}=3.5446 \mathrm{MeV}$ was identified as the analog of the $3.06 \mathrm{MeV}^{59} \mathrm{Ni}$ state. Utilizing the technique of Thompson, Adams, and Robson ${ }^{27}$ a spectroscopic factor $\left[(2 J+1) C^{2} S\right]$ of 1.5 is obtained compared to our value of 0.70 . However, Arai et al.$^{10}$ point out that they were unable to obtain reasonable criteria for determining the matching radius upon which the spectroscopic factor critically depends. As can be seen in Table IV, the spectroscopic factor extracted from the data of Arai et al..$^{10}$ utilizing the simple optical model technique is in agreement with the $\left({ }^{3} \mathrm{He}, d\right)$ result.

\section{STRUCTURE CALCULATIONS WITH THE PARTICLE- CORE-COUPLING MODEL}

In a simple shell-model prescription, one would expect that for the $\mathrm{Ni}$ isotopes $(Z=28)$, the proton $1 d_{5 / 2}, 2 s_{1 / 2}, 1 d_{3 / 2}$, and $1 f_{7 / 2}$ subshells are completely filled and all other higher orbitals are empty. Therefore, the structure of low-lying levels in ${ }^{59} \mathrm{Cu}$, where one proton has been added to the ${ }^{58} \mathrm{Ni}$ core should be simple and easy to describe. However, shell-model calculations of Singh et al. ${ }^{28}$ could not describe the structure of
${ }^{59} \mathrm{Cu}$ adequately. Using a unified model, Castel et al..$^{29}$ have been successful in reproducing a few of the low-lying states. Larner ${ }^{30}$ has calculated the structure of $N=29$ or $Z=29$ nuclei using a simple core-coupling model with reasonable success but he did not do calculations for ${ }^{59} \mathrm{Cu}$ due to lack of enough experimental data at that time. We have used a similar model to predict the negative parity $\frac{1}{2}-^{-}, \frac{3-}{2}, \frac{5^{-}}{2}, \frac{7}{2}^{-}$, and $\frac{9}{2}^{-}$states of ${ }^{59} \mathrm{Cu}$ by coupling of the protons in $2 p_{1 / 2}, 2 p_{3 / 2}$, and $1 f_{5 / 2}$ orbitals with the $0^{+}$ground state and the first $2^{+}$ state of ${ }^{58} \mathrm{Ni}$. Details of this model are given elsewhere. ${ }^{17}$ The values of Hamiltonian parameters $\chi_{1}, \chi_{2}$, and $\eta$, defined in Ref. 17, were fixed to be $0.47 \mathrm{MeV} \mathrm{fm}^{-2}, 0.48 \mathrm{MeV} \mathrm{fm}^{-2}$, and $0.28 \mathrm{MeV}$, respectively, in accordance with those used by Larner in his analysis of other $\mathrm{Cu}$ isotopes ( $A$ $=61,63$, and 65). The single-particle energies were taken as $\epsilon_{1}=\epsilon\left(p_{1 / 2}\right)-\epsilon\left(p_{3 / 2}\right)=0.85 \mathrm{MeV}$ and $\epsilon_{2}=\epsilon\left(f_{5 / 2}\right)-\epsilon\left(p_{3 / 2}\right)=1.15 \mathrm{MeV}$.

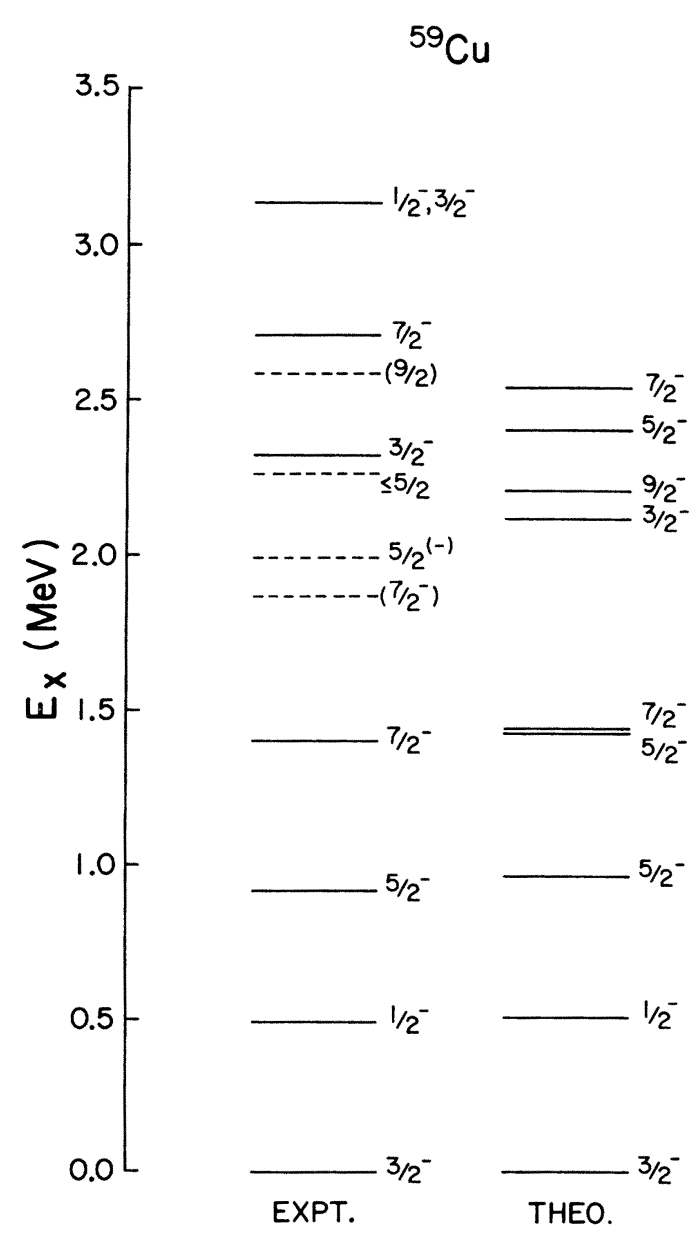

FIG. 8. Comparison of the experimental levels with the theoretical predictions for ${ }^{59} \mathrm{Cu}$. The $J^{\pi}$ values are indicated on the right. 
Theoretical and experimental results for ${ }^{59} \mathrm{Cu}$ up to $3.4 \mathrm{MeV}$ in excitation are shown in Fig. 8 and the agreement is excellent for the first four levels with respect to both energy location and $J^{\pi}$ assignments. In this figure, we have also included as dashed lines the possible negative-parity levels that were not observed in the present study but were included in the decay scheme by Nelson et $a l .{ }^{7}$ Although the comparison of these states with theory could be speculative, it appears that the observed $\frac{5}{2}^{(-)}$state at $1.988 \mathrm{MeV}$ corresponds to the $\frac{5-}{2}$ state predicted at $1.43 \mathrm{MeV}$. The higher experimental states, namely the $\frac{3}{2}^{-},\left(\frac{9}{2}\right)$, and $\frac{7}{2}^{-}$ states between 2.3 and $2.7 \mathrm{MeV}$ in excitation agree in the order and the $J$ assignments with those predicted but are about $100 \mathrm{keV}$ lower. The higher states are not shown as they are unbound to proton decay.

\section{CONCLUSIONS}

The $\left({ }^{3} \mathrm{He}, d\right)$ reaction at 35 and $39 \mathrm{MeV}$ bombarding energies has been used to populate the proton states of ${ }^{59} \mathrm{Cu}$. The usual DWBA analysis was made for the states below $3.4 \mathrm{MeV}$ to make $l$ assignments and to extract spectroscopic factors. The results obtained for these states in the present study agreed very well with previous studies. At higher energy, we analyzed levels up to 9.25 $\mathrm{MeV}$ in excitation and many new levels have been identified. DWBA analysis of these proton-unstable states above $3.4 \mathrm{MeV}$ was done for the present $\left({ }^{3} \mathrm{He}, d\right)$ reaction data, the $(d, n)$ reaction data of Marusak with $E_{d}=10 \mathrm{MeV}$, and the $\left({ }^{3} \mathrm{He}, d\right)$ reaction work of Blair and Armstrong with $E_{3 \mathrm{He}}=22 \mathrm{MeV} . \quad l$ assignments and the spectroscopic factors were extracted and in general are in good agreement for the different reactions. The levels seen in the present study between $3.74 \leqslant E_{x} \leqslant 5.96 \mathrm{MeV}$ probably belong to $2 p_{3 / 2}, 2 p_{1 / 2}$, and $1 f_{5 / 2}$ orbitals, whereas most of the levels at higher excitation energy belong to $1 g_{9 / 2}$ and $2 d_{5 / 2}$ orbitals as expected.

Twelve levels are identified as likely analogs of levels in ${ }^{59} \mathrm{Ni}$. The spectroscopic factors for most of the analogs are in agreement with parent state spectroscopic factors obtained from ${ }^{58} \mathrm{Ni}(d, p) .{ }^{24-26}$ However, the spectroscopic factor for the $g_{9 / 2}$ state at $6.917 \mathrm{MeV}$ is about 0.70 , much smaller than the expected value of 2.9. Our value is in agreement with the value of 0.57 we obtain using the ${ }^{58} \mathrm{Ni}(p, p)$ data of Arai et al. ${ }^{10}$

A simple core-coupling model is used to predict the properties of low-lying levels in ${ }^{59} \mathrm{Cu}$. The calculated results are in good agreement with experimental data. Because the levels above 3.42 $\mathrm{MeV}$ are proton unbound, comparison is restricted to levels below this energy.

The authors wish to thank R. Weber and R. Hartley for their assistance in taking and analyzing the data and B. E. Cooke (Queens University) for calculating the single-particle widths.
†Work supported in part by the National Science Foundation and the Robert A. Welch Foundation.

*Present address: Physics Department, Queens University, Kingston, Ontario, Canada.

${ }^{1}$ A. G. Blair and D. D. Armstrong, Phys. Lett. 16, 57 (1965).

${ }^{2}$ G. C. Morrison and J. P. Schiffer, Isobaric Spin in Nuclear Physics, edited by J. D. Fox and D. Robson (Academic, New York, 1966), p. 748.

${ }^{3}$ D. J. Pullen and B. Rosner, Phys. Rev. 170, 1034 (1968).

${ }^{4}$ A. Marusak, Oak Ridge National Laboratory Report No. ORNL-TM-2472, 1969 (unpublished).

${ }^{5}$ J. Bommer, H. Fuchs, K. Grabish, H. Kluge, W. Ribbe, and G. Röschert, Nucl. Phys. A199, 115 (1973).

${ }^{6} \mathrm{P}$. Roussel, G. Bruge, A. Buissiere, H. Faraggi, and J. E. Testoni, Nucl. Phys. A155, 306 (1970).

${ }^{7}$ R. O. Nelson, C. R. Gould, D. R. Tilley, and N. R. Robertson, Phys. Rev. C 9, 2193 (1974).

${ }^{8}$ I. M. Borkin et al ., Izv. Akad. Nauk SSSR Ser. Fiz. 30, 271 (1966) [Bull. Acad. Sci. (USSR), Phys. Ser. $\underline{30}$, 277 (1967)] .

${ }^{9}$ J. C. Browne, H. W. Newson, E. G. Bilpuch, and G. E. Mitchell, Nucl. Phys. A153, 481 (1970).

${ }^{10}$ E. Arai, M. Ogawa, and H. Sato, Nucl. Phys. A256, 127 (1976).

${ }^{11}$ H. V. Klapdor, M. Schrader, G. Bergdolt, and A. M.
Bergdolt, Nucl. Phys. A245, 133 (1975).

${ }^{12}$ B. E. Cooke, J. R. Leslie, B. C. Robertson, and W. Mc Latchie, Can. J. Phys. $\underline{53}, 2506$ (1975).

${ }^{13}$ J. P. Trentelman, B. E. Cooke, J. R. Leslie, W. McLatchie, and B. C. Robertson, Nucl. Phys. A246, 457 (1975).

${ }^{14}$ D. H. Youngblood, R. L. Kozub, R. A. Kenefick, and J. C. Hiebert, Phys. Rev. C 2 , 477 (1970).

${ }^{15}$ C. M. Vincent and H. T. Fortune, Phys. Rev. C $\underline{2}, 782$ (1970).

${ }^{16}$ R. L. Kozub and D. H. Youngblood, Phys. Rev. C $\underline{4}, 535$ (1971); 5, 413 (1972).

${ }^{17}$ P. K. Bindal, D. H. Youngblood, R. L. Kozub, and P. H. Hoffmann-Pinther, Phys. Rev. C 12 , 390 (1975).

${ }^{18}$ Received from P. D. Kunz, University of Colorado.

${ }^{19}$ P. P. Urone, L. W. Put, B. W. Ridley, and G. D. Jones, Nucl. Phys. A167, 383 (1971).

${ }^{20}$ C. M. Perey and F. G. Perey, Phys. Rev. 152,926 (1966).

${ }^{21}$ J. C. Hiebert and E. Newman, Nucl. Phys. 113, 179 (1968).

${ }^{22}$ E. Newman, L. C. Becker, and B. M. Preedom, Nucl. Phys. 100, 225 (1967).

${ }^{23}$ J. Vervier, Nucl. Data B2 (No. 5), 1 (1968).

${ }^{24}$ R. H. Fulmer, A. L. McCarthy, B. L. Cohen, and

R. Middleton, Phys. Rev. 133, B955 (1964).

${ }^{25}$ E. R. Cosman, C. H. Paris, A. Sperduto, and H. A. 
Enge, Phys. Rev. 142, 673 (1966).

${ }^{26}$ M. S. Chowdhury and H. M. Sen Gupta, Nucl. Phys. A205, 454 (1973).

${ }^{27}$ W. J. Thomson, J. L. Adams, and D. Robson, Phys. Rev. 173 , 975 (1968).
${ }^{28}$ R. P. Singh, R. Raj, M. L. Rustgi, and H. W. Kung, Phys. Rev. C 2,1715 (1970).

${ }^{29}$ B. Castel, I. P. Johnstone, B. P. Singh, and K. W. C. Stewart, Can. J. Phys. 50, 1630 (1972).

${ }^{30}$ D. Larner, Phys. Rev. C $\underline{2}, 522$ (1970). 